\title{
A Cross-Cultural Perspective on Factors that Influence the Intention to Repurchase in Online Marketplaces: A Comparison Between Thailand and Germany
}

\author{
Bastian Eine \\ Faculty of Design, Computer Science, Media, RheinMain University of Applied \\ Sciences, Wiesbaden, Germany \\ Peerayuth Charoensukmongkol \\ International College, National Institute of Development Administration, Bangkok, \\ Thailand
}

\section{Abstract}

This research examines the effect of perceived usefulness, perceived ease of use, trust in the sellers, and perceived sellers' risk on the intention to repurchase in online marketplaces by respondents from Thailand and Germany. This research also integrates the theoretical framework of cultural values to explore whether these determinants' effect on the intention to repurchase in online marketplaces differs significantly between the respondents from these two nations. Online survey data were collected from 404 Thai and 405 German participants, and partial least squares structural equation modeling was used for data analysis. The results confirmed the significant effect of perceived usefulness, perceived ease of use, trust in the sellers, and perceived sellers' risk on the intention to repurchase in online marketplaces. Moreover, the moderating effect analysis showed that the effect of perceived usefulness, perceived ease of use, and trust in the sellers were significantly higher in Thai than in German respondents. However, there was no significant difference between the two nationalities in the effect of perceived sellers' risk on the intention to repurchase in online marketplaces.

Keywords: E-Commerce, National Culture, Online Shopping, Cross-Cultural Analysis, Online Marketplaces. 


\section{Introduction}

To develop international and national online shopping, it is important to understand why consumers intend to buy online (Tarsakoo \& Charoensukmongkol, 2019). Consumers' characteristics, beliefs, perceptions, and behaviors have often been the main focus of academic and market research that was designed to analyze the motivators of, and barriers to, online shopping (Chaparro-Peláez, Agudo-Peregrina, \& Pascual-Miguel, 2016). Researchers have stated that e-commerce is still not developed fully and better research on online consumers' shopping intentions is necessary (Aldousari, Delafrooz, Ab Yajid, \& Ahmed, 2016). Customers' intention to use online shopping is of great interest and importance for not only e-commerce researchers but also online retailers to develop new strategies to increase online sales.

Despite the abundance of prior research that has examined the determinants of online shopping intention, only a limited number of studies has addressed the cross-cultural perspective to clarify the way different cultures can influence the determinants of online shopping intention. Relatively little research has been conducted that has tried specifically to explain the cross-cultural differences in the intention to use online shopping (e.g., see Chopdar, Korfiatis, Sivakumar, and Lytras (2018) and Lu, Yu, Liu, and Wei (2017)). This cross-cultural view of online shopping is important because of the increasing internationalization and globalization of online shopping, and the diffusion of multinational online shopping platforms as well. Online consumers may differ between countries because of different national environments (e.g., economic, infrastructural, or cultural environment), individual cultural perspectives, different lifestyles, ways of thinking, and perceptions (Charoensukmongkol, 2020; Pandey \& Charoensukmongkol, 2019). National culture is one component that can shape consumers' characteristics, beliefs, and perceptions. On the one hand, individuals can differ in their cultural characteristics within countries as well (McCoy, Galletta, \& King, 2005). On the other, some countries may have higher values in certain cultural dimensions than other countries in general (Charoensukmongkol \& Pandey, 2020). Hence, it is important to analyze customers from countries with different cultural backgrounds to determine culture's role in online shopping.

Theories and studies on cultural dimensions have shown that Thailand and Germany hold different cultural values (Hall, 1989; Hofstede, Hofstede, \& Minkov, 2010). Hofstede et al. (2010) assumed that Thailand is a high power distance culture in which inequalities are more accepted, strict chains of command are more common, approaching managers is more formal, and information flows hierarchically compared to low power distance countries (Phungsoonthorn \& Charoensukmongkol, 2019). In contrast to Thailand, Germany has a low score on power distance, and direct communication and participation in decision making are common (Hall, 1989). While Germany is assumed to be a highly individualistic culture, Thailand represents a highly collectivistic country. Germany is considered to be a masculine society that values performance, while Thailand is assumed to be a feminine society that is less assertive and competitive (Seriwatana \& Charoensukmongkol, 2020). According to Hofstede et al. (2010), Thailand and Germany have similar scores on the dimension of uncertainty avoidance, and thus Hofstede et al. (2010) assumed that both countries prefer strict rules, laws, policies, and regulations that reduce uncertainty. Therefore, analyzing Thailand and Germany can illustrate that international research can benefit from findings on countries with different cultures (i.e., Asian and European) and validate 
international research findings.

Given the issues mentioned above, this study's first objective is to examine the determinants of the intention to repurchase in online marketplaces with respect to perceived usefulness, perceived ease of use, trust in the sellers, and perceived sellers' risk. These factors have been shown to be important predictors that explain consumers' intention to buy online in general (Chopdar et al., 2018; Driediger \& Bhatiasevi, 2019; Marriott \& Williams, 2018) and in online marketplaces specifically (Gefen \& Pavlou, 2012). Importantly, this research integrates the cross-cultural perspective by using survey data collected from two countries, Thailand and Germany. In addition to these determinants' direct effect, this research explored whether their effect on the intention to repurchase in online marketplaces differed significantly between the Thai and German respondents. This research is grounded in the theoretical framework of cultural values to justify the cultural differences between Thailand and Germany and uses this theoretical framework to explain why people in these two nations may vary in their intention to repurchase in online marketplaces.

\section{Literature Review}

\section{Intention to Repurchase in Online Marketplaces}

Different technologies are available to buy products online, e.g., online shops, online marketplaces, or social media. This study focuses on online marketplaces because of the increasing economic success of online marketplaces and relatively little research about this type of online shopping. An online marketplace is managed by an intermediary and used by several different vendors to sell their products online at the same virtual location. The behavior of interest in this study is the consumers' intention to use online marketplaces again to make a purchase. Behavioral intention to use describes an individual's intention to perform a given behavior, and it is the motivation for an individual' future behavior (Davis, Bagozzi, \& Warshaw, 1989). Behavioral intention does not guarantee the actual behavior to use the online marketplace but is an essential variable that influences the actual use behavior. Perceived usefulness, perceived ease of use, trust in the sellers, and perceived sellers' risk are factors that are important not only in accepting technology in general but also online marketplaces specifically. While perceived usefulness and perceived ease of use are technological predictors, trust and risk perceptions are social predictors of online shopping.

\section{Perceived Usefulness}

In the consumer context, perceived usefulness is "...the degree to which using a technology will provide benefits to consumers in performing certain activities" (Venkatesh, Thong, \& Xu, 2012, p. 159). Adapted to online shopping, perceived usefulness is the consumer's expected benefit of using online shopping to make a purchase. Consumers who find buying in online marketplaces useful are likely to intend to buy in online marketplaces in the future, as they expect to obtain advantages from using this form of shopping compared to other ways of shopping. Several studies have proven that perceived usefulness has a positive influence on the behavioral intention to use online shopping (Chopdar et al., 2018; Driediger \& Bhatiasevi, 2019; Natarajan, Balasubramanian, \& Kasilingam, 2017). This relation had been shown to be strong in 
other technological environments as well, e.g., internet banking (Martins, Oliveira, \& Popovič, 2014) and mobile payment (Alshare \& Mousa, 2014). Therefore, we propose the following hypothesis:

H1 There is a positive relationship between perceived usefulness of online marketplaces and the intention to repurchase in online marketplaces.

\section{Perceived Ease of Use}

Perceived ease of use is "...the degree of ease associated with consumers' use of technology" (Venkatesh et al., 2012, p. 159). It is a measure of the perceived effort that the user expects to learn and use the technology (Gefen, Karahanna, \& Straub, 2003). Adapted to the context of online shopping, perceived ease of use is the extent to which a consumer believes that the interaction with the online shopping platform required to make purchases will be effortless. Consumers who find buying in online marketplaces easy are likely to intend to buy in online marketplaces in these marketplaces in the future, as they do not expect to be challenged by complex shopping processes that require a high level of cognitive or physical effort. Studies of online shopping have shown that consumers' perceived ease of use has a positive influence on their intention to shop online (Driediger \& Bhatiasevi, 2019). This relation has also been confirmed for internet banking (Martins et al., 2014) and mobile commerce (Chopdar et al., 2018; Natarajan et al., 2017). Therefore, the following hypothesis is presented:

$\mathrm{H} 2$ There is a positive relationship between perceived ease of use of online marketplaces and the intention to repurchase in online marketplaces.

\section{Trust in Sellers}

In general, trust is defined as an individual's or group's confidence in relying on another individual's or group's work, promise, or oral or written statement (Rotter, 1967). Customers' subjective set of beliefs about the vendor's characteristics and possible behavior shape trust (Flavián \& Guinalíu, 2006). In the online shopping context, trust constructs and the mechanisms in building trust are of particular interest because of the lack of interpersonal communication in online shopping (Chang, Cheung, \& Tang, 2013). Trust in sellers is defined as the "... buyer's subjective belief that online transactions with sellers [...] will occur in a manner consistent with his or her expectations of trustworthy behavior" (Pavlou \& Gefen, 2004, p. 40). Consumers who do not trust sellers in online marketplaces are unlikely to intend to buy in those marketplaces, as they will try to avoid the difficulties caused by sellers who do not keep their promises. In previous studies, trust has proven to have a positive influence on the intention to buy online (Marriott \& Williams, 2018). Therefore, we propose the following hypothesis:

H3 There is a positive relationship between trust in the sellers and the intention to repurchase in online marketplaces. 


\section{Perceived Sellers' Risk}

While trust is often associated with social vulnerability, risk is associated largely with economic vulnerability (Gefen \& Pavlou, 2012). In the consumer context, Bauer (1960) defined risk as the degree of uncertainty that a consumer perceives in a purchase decision. In online shopping, risks preexist because of the internet's nature and basic structure. Consumers can feel confused and, particularly in a purchase decision in a virtual, online environment, may experience uncertainty and fear possible risks (Chaparro-Peláez et al., 2016). Perceived sellers' risk is defined as the "...buyers' perception that there is some probability of suffering a loss when pursuing transactions among members of the community of sellers" (Pavlou \& Gefen, 2004, p. 41). Consumers who perceive a high risk in sellers in online marketplaces are unlikely to intent to buy in online marketplaces, as they will try to avoid potential losses because of uncertainties about sellers. Previous studies have shown that risk had a negative influence on the behavioral intention to use online shopping (Chang, Fu, \& Jain, 2016). These findings were supported by Marriott and Williams (2018) who showed that performance and financial risks had a negative effect on the intention to buy online. Therefore, we propose the following hypothesis:

H4 There is a negative relationship between perceived sellers' risk and the intention to repurchase in online marketplaces.

\section{Moderating Effect of National Cultures}

Hofstede (2010) and Hall's (1989) frameworks are used most widely to describe a nation's different cultural characteristics according to several cultural dimensions. Culture influences members' perceptions, thinking, the way they evaluate, and their behavior, and it defines members' affiliation with a society (Puyod \& Charoensukmongkol, 2019). Cultural frameworks have been shown to be able to explain national culture's influence on technology use, for example, Hallikainen and Laukkanen (2018) showed that cultural dimensions have an indirect influence on consumers' perceived trustworthiness of an online shop. Zhang, Weng, and Zhu (2018) confirmed that cultural dimensions moderated the effect of the independent variables of the technology acceptance model in electronic banking context. Based upon the literature review (e.g., Hallikainen and Laukkanen (2018), Chopdar et al. (2018), and $\mathrm{Lu}$ et al. (2017)), the differences in cultural values with respect to masculinity, uncertainty avoidance, and collectivism may be the major aspects of cultural values that explain why people from different countries may have different online shopping purchase intentions.

First, this research proposes that the effect of perceived usefulness of online marketplaces and the intention to repurchase in online marketplaces is stronger in a culture that is high in masculinity than in one that is low in masculinity. Masculinity versus femininity is a cultural dimension that describes the extent to which a society values achievement, competition, and assertiveness more than cooperation and relationships (Hofstede et al., 2010). In cultures with high masculinity scores, economic success and materials are symbols of wealth. In contrast, feminine cultures focus more on the quality of life, modesty, and caring for the weak (Beugelsdijk \& Welzel, 2018). In general, online shopping is considered to be a highly efficient way to shop compared to other ways of shopping because of the high transparency of product prices, large 
product variety, less time spent searching for specific products, and ability to shop at home than in brick-and-mortar stores (Rita, Oliveira, \& Farisa, 2019). If consumers have these high performance expectations of online shopping, they are more likely to use this way of shopping. People in cultures with a high masculinity score tend to value performance highly (Pandey \& Charoensukmongkol, 2019), and previous studies have shown that the influence of perceived usefulness on the behavioral intention to use online shopping is stronger in highly masculine cultures (Alshare \& Mousa, 2014; Yoon, 2009). Thus, the following hypothesis is proposed:

H5 The positive relationship between perceived usefulness of online marketplaces and the intention to repurchase in online marketplaces is stronger in a culture high in masculinity.

Second, this research proposes that the effect of perceived ease of use of online marketplaces and the intention to repurchase in online marketplaces is stronger in the culture high in uncertainty avoidance than in one low in uncertainty avoidance. This cultural dimension describes the extent to which members of a society experience anxiety under uncertain circumstances (Hofstede et al., 2010). Cultures with high uncertainty avoidance wish to have clear rules, guidance, social norms, fixed habits, rituals, and bureaucratic processes, and try to add structure and control to their environments in general to avoid the uncomfortable feeling of unknown, novel, surprising and unstructured situations (Beugelsdijk \& Welzel, 2018). In contrast, cultures with low uncertainty avoidance are risk takers who are tolerant of deviance and less formal rules and norms. People with high uncertainty avoidance may be more concerned about perceived ease of use of online marketplaces. While shopping in online marketplaces has several uncertainties because of the lack of direct transactions with people, the shopping process itself is structured clearly. Hung and Chou (2014) and Lu et al.'s (2017) previous studies of mobile commerce showed that the relationship between perceived ease of use and online purchase intention was stronger in cultures with high uncertainty avoidance. This supports the view that consumers who prefer clear instructions and procedures rather than unknown situations intend to use online shopping more frequently when they perceive that the online shopping platform is structured clearly and easy to use. Thus, the following hypothesis is proposed:

H6 The positive relationship between perceived ease of use of online marketplaces and the intention to repurchase in online marketplaces is stronger in the culture high in uncertainty avoidance.

Third, this research proposes that the effect of trust in the sellers and the intention to repurchase in online marketplaces is stronger in a culture with high collectivism than in one with low collectivism. This cultural dimension describes the extent to which a society's members prefer a loosely knit social framework in which people are expected to make individual choices and decisions (Hofstede et al., 2010). In highly individualistic cultures, people tend to put more value on their own interests than on those of the group (Beugelsdijk \& Welzel, 2018). Thus, people's behavior in individualistic cultures is characterized by autonomy rather than group action. Further, individual accomplishments and rewards are preferred and members of the society are more open to individual opinions and behavior but have little loyalty to other people and institutions as they often act individually and competitively. While individualism favors equity over equality, collectivism is characterized by equity for out-groups only 
and equality for in-groups (Beugelsdijk \& Welzel, 2018). Hence, collectivism describes the extent to which a society's members prefer a tightly knit social framework with strong loyalty to other group members and strong interpersonal ties that focus on the community's goals (Pongton \& Suntrayuth, 2019). Individualistic societies are more likely to trust others in the online shopping context than are collectivistic cultures (Pavlou, 2003), as cultures with high collectivism scores have less trust in out-groups (Seriwatana \& Charoensukmongkol, 2020). Hence, trust is expected to be more important in collectivist cultures than in individualistic cultures (Ratasuk \& Charoensukmongkol, 2020). Further, face-to-face communication is not present in online shopping. Thus, it is difficult for consumers to perceive the sellers' actions and behaviors (Rita et al., 2019). In collectivistic cultures, personal relationships are important when conducting business (Hofstede et al., 2010), and building such relationships online takes time. Building trust also takes more time in collectivistic cultures than in individualistic cultures. Therefore, the following hypothesis is proposed:

H7 The positive relationship between trust in the sellers and the intention to repurchase in online marketplaces is stronger in the culture with high collectivism.

Fourth, the research proposes that the negative effect of perceived sellers' risk and the intention to repurchase in online marketplaces is stronger in a culture high in uncertainty avoidance than in one low in uncertainty avoidance. Uncertainty about sellers' behavior, incomplete information about the product, and potential misuse of personal information are risks and unknown situations that consumers face when shopping online (Rita et al., 2019). In general, privacy and security concerns tend to be greater in high uncertainty avoidance cultures (Beugelsdijk \& Welzel, 2018). As people in these cultures feel anxious in uncontrollable situations, they will avoid using online marketplaces when they perceive high sellers' risk (Sohaib, Kang, \& Miliszewska, 2019). Previous studies have shown that cultures high in uncertainty avoidance also have high perceived risk in shopping online and this has a negative influence on their intention to shop online (Driediger \& Bhatiasevi, 2019). In contrast, people in cultures with low uncertainty avoidance tend to have a greater tolerance for risk and thus may be more willing to take a risk when interacting with sellers in online marketplaces. Thus, the following hypothesis is proposed:

H8 The negative relationship between perceived sellers' risk and the intention to repurchase in online marketplaces is stronger in the culture high in uncertainty avoidance.

\section{Research Method}

\section{Sample Selection and Data Collection Procedure}

The study's target population was online consumers from Thailand and Germany. Convenience sampling was used to select the sample. This sampling method can be used when randomization is impossible, particularly when the population is virtually limitless (Andres, 2012). Therefore, this sampling method is appropriate for the research given that the population of online consumers is generally large in scope. A 
professional panel provider invited respondents to participate online. The panel included consumers from Thailand and Germany. As pre-screen criteria, respondents had to be at least 20 years old, Thai or German, and Thai respondents had to have used the most popular online marketplace in Thailand (i.e., lazada.co.th) and German respondents the most popular online marketplace in Germany (i.e., amazon.de) at least once. Thus, the consumers were able to respond based on their actual perceptions and experience. Both online marketplaces are very similar with respect to the website, app design, and navigation, as well as the purchasing process. The sampling frame was the respective consumers in the online panel who matched the pre-screen criteria. Data were collected in the form of a structured online questionnaire. A group of university staff and online consumer reviewed the questionnaire to evaluate the item's face validity and clarity. The German author of this study and two independent professional translators conducted the translation and back-translation of the questionnaire to ensure translation equivalence. A pretest was conducted in Thailand and Germany to obtain information about the questionnaire items' reliability and validity. The online consumers were informed of the purpose of the study and were assured of their anonymity and the confidentiality of their responses, and the questionnaire was administered to them with their consent. The data were collected between February 28 and March 12, 2020. According to Yamane's formula (Israel, 1992) a sample size of 400 is required to achieve the 95 percent significance level. Thus, this study targeted a sample size of 400 in each country to collect statistically suitable data. The sample size in the study fulfilled the requirement, as it was 404 in Thailand and 405 in Germany. The minimum sample size was also justified by the inverse square root and gammaexponential methods, which are the recommended minimum sample size estimation in variance-based structural equation model analysis (Kock \& Hadaya, 2018). According to Kock and Hadaya (2018), these methods simulate Monte Carlo experiments, and thus produce estimates that are in line with the estimates that would be produced through the Monte Carlo method. According to the estimation, the inverse square root method recommended the minimum sample size of 160, whereas the Gamma-exponential method recommended the minimum sample size of 146. Our sample size obtained from both countries met these recommended requirements.

The percentage of female and male respondents in both samples were nearly equally distributed, with $54.7 \%$ females in the Thai sample and 52.8\% in the Germany sample, respectively. Overall, the German respondents were somewhat older than the Thai respondents. While more than half of the Thai respondents stated that they have a Bachelor's degree (58.2\%), most of the German respondents indicated that vocational training $(40.5 \%)$ was their highest educational qualification. The samples' demographics are presented in Tables 1 and 2. 
Table 1: Demographic Characteristics

\begin{tabular}{lcccc}
\hline & \multicolumn{2}{c}{ Thailand } & \multicolumn{2}{c}{ Germany } \\
& Frequency & Percentage & Frequency & Percentage \\
\hline Gender & & & & \\
Female & 221 & 54.7 & 214 & 52.8 \\
Male & 183 & 45.3 & 191 & 47.2 \\
& & & & \\
Age & & & & \\
$20-24$ & 27 & 6.7 & 22 & 5.4 \\
$25-29$ & 52 & 12.9 & 40 & 9.9 \\
$30-34$ & 87 & 21.5 & 73 & 18.0 \\
$35-39$ & 65 & 16.1 & 48 & 11.9 \\
$40-44$ & 66 & 16.3 & 91 & 22.5 \\
$45-49$ & 31 & 7.7 & 40 & 9.9 \\
$50-54$ & 50 & 12.4 & 37 & 9.1 \\
$55-59$ & 20 & 5.0 & 29 & 7.2 \\
$60-64$ & 6 & 1.5 & 24 & 5.9 \\
65 or older & 0 & 0.0 & 1 & 0.2 \\
& & & & \\
Educational qualification & & & & \\
No degree & 0 & 0.0 & 1 & 0.2 \\
Secondary school qualification & 8 & 2.0 & 12 & 3.0 \\
High school diploma & 24 & 5.9 & 53 & 13.1 \\
University entrance qualification & 44 & 10.9 & 52 & 12.8 \\
Completed vocational training & 56 & 13.9 & 164 & 40.5 \\
Bachelor' degree & 235 & 58.2 & 56 & 13.8 \\
Master's degree & 32 & 7.9 & 65 & 16.0 \\
PhD & 5 & 1.2 & 2 & 0.5 \\
\hline
\end{tabular}

Table 2: Respondents' Income

\begin{tabular}{|c|c|c|c|c|c|}
\hline \multicolumn{3}{|c|}{ Thailand } & \multicolumn{3}{|c|}{ Germany } \\
\hline Less than 5,000 Baht & 8 & 2.0 & Less than 500 Euro & 19 & 4.7 \\
\hline $5,000-10,000$ Baht & 35 & 8.7 & 500 - 1,000 Euro & 42 & 10.4 \\
\hline $10,001-20,000 \mathrm{Baht}$ & 107 & 26.5 & 1,001 - 1,500 Euro & 52 & 12.8 \\
\hline $20,001-30,000 \mathrm{Baht}$ & 102 & 25.2 & 1,501 - 2,000 Euro & 56 & 13.8 \\
\hline $30,001-50,000$ Baht & 100 & 24.8 & 2,001 - 2,500 Euro & 74 & 18.3 \\
\hline $50,001-80,000$ Baht & 28 & 6.9 & 2,501 - 3,000 Euro & 47 & 11.6 \\
\hline More than 80,000 & 20 & 5.0 & More than 3,000 & 81 & 20.0 \\
\hline Baht & & & Euro & & \\
\hline Not specified & 4 & 1.0 & Not specified & 34 & 8.4 \\
\hline
\end{tabular}

The comparison of the Thai and German respondents' cultural values was determined by the individual-level data. The cultural values in the aspects of masculinity, uncertainty avoidance, and collectivism were measured by the scale Yoo, Donthu, and Lenartowicz (2011) developed, which is very similar to that of Srite and Karahanna (2006), which is cited frequently in information system research. Yoo et al. (2011) adapted Srite and Karahanna's (2006) scale to the consumer context. Srite and Karahanna (2006) measured the espoused national cultural values on the individual level in the technology acceptance context. This approach has been used in other studies in online shopping (Yoon, 2009) and mobile payment (Alshare \& Mousa, 2014) as well. 
Masculinity, uncertainty avoidance, and collectivism were measured by 3 items each. Following the method suggested in previous research (e.g., Pandey and Charoensukmongkol (2019)), the mean score of each of these cultural values was calculated, and then they were compared with a t-test. The results shown in Table 3 indicate that the mean scores of the cultural values are significantly higher for the Thai than for the German respondents.

Table 3: Cultural Differences

\begin{tabular}{lcccc}
\hline Variables & Mean: Thai & Mean: German & $\begin{array}{c}\text { Mean } \\
\text { difference }\end{array}$ & p-value \\
\hline Masculinity & 3.44 & 3.28 & .16 & $<.001$ \\
Uncertainty & 4.06 & 4.03 & .03 & $<.001$ \\
$\begin{array}{l}\text { avoidance } \\
\text { Collectivism }\end{array}$ & 3.71 & 3.61 & .10 & $<.001$ \\
\hline
\end{tabular}

\section{Measures}

The variables of technology acceptance were measured using the scales from Gefen et al. (2003) and Venkatesh et al. (2012), Altogether, the scales included a total of 10 items for the technology acceptance constructs. The perceived usefulness, perceived ease of use, and online shopping intention variables were measured on a five-point Likert scale that ranged from 1 (strongly disagree) to 5 (strongly agree).

Trust in the sellers was measured by adapting Pavlou and Gefen (2004)'s scale. This scale consists of three items: The community of sellers' perceived (1) reliability; (2) honesty, and (3) trustworthiness. This variable was measured on the same Likert scale as above. The scale's reliability and validity were tested and confirmed in Gefen and Pavlou (2012) as well.

Perceived sellers' risk was measured using Pavlou and Gefen's (2004) scale, which consists of three items: The perception of (1) risk involved in making a purchase; (2) potential for loss, and (3) a risky decision. The variable was also measured on the same Likert scale as above, and the scale's reliability and validity was tested and confirmed in Gefen and Pavlou (2012).

\section{Control Variables}

The respondents' demographic characteristics that might affect online shopping were used as control variables, and were their gender, age, education, income, and nationality.

\section{Data Analysis}

The partial least squares structural equation model (PLS-SEM) was used in the data analysis. PLS-SEM is a suitable method to analyze a conceptual model that incorporates latent variables with multiple indicators, and when the analysis of multiple moderating effects is involved in model estimation. This method was appropriate for this research, as it contains four hypotheses that involve moderation. PLS-SEM was performed using WarpPLS software version 6.0. 


\section{Results}

First, validity and reliability tests were performed. Convergent validity was confirmed by factor loadings, which must exceed .7 (Fornell \& Larcker, 1981). This requirement was met in the analysis. Discriminant validity was confirmed by the heterotraitmonotrait ratio of correlations (HTMT). All HTMTs between the constructs were below the suggest threshold of .9 and their confidence intervals did not contain the value 1 (Henseler, Ringle, \& Sarstedt, 2015). Thus, the results satisfied the discriminant validity requirement and are reported in Table 4.

Table 4: Heterotrait-monotrait Ratio of Correlations

\begin{tabular}{lcccc}
\hline Variables & PU & PEOU & BI & TRS \\
\hline PU & & & & \\
PEOU & .759 & & & \\
BI & .791 & .64 & & \\
TRS & .674 & .575 & .601 & \\
RSK & .579 & .554 & .513 & .649 \\
\hline
\end{tabular}

Notes: PU=perceived usefulness of online marketplace, PEOU=perceived ease of use of online marketplace, $\mathrm{BI}=$ online shopping intention, TRS=trust in the sellers, $\mathrm{RSK}=$ perceived sellers' risk

Next, the construct reliability was evaluated using Cronbach's alpha and composite reliability coefficients, which must be greater than .7 (Bagozzi \& Yi, 1988; Chin, 1998). These indicators were shown in the measures section above, and all met the requirement. The results are presented in Table 5.

Table 5: Cronbach's Alpha and Composite Reliability Coefficients

\begin{tabular}{lccccc}
\hline Variables & PU & PEOU & BI & TRS & RSK \\
\hline Cronbach's Alpha Coefficients & .832 & .892 & .862 & .923 & .925 \\
Composite Reliability Coefficients & .899 & .925 & .916 & .951 & .952 \\
\hline
\end{tabular}

Notes: PU=perceived usefulness of online marketplace, PEOU=perceived ease of use of online marketplace, $\mathrm{BI}=$ online shopping intention, $\mathrm{TRS}=$ trust in the sellers, $\mathrm{RSK}=$ perceived sellers' risk.

Lastly, multicollinearity was evaluated by the full variance inflation factor (VIF), which must be below 3.3. The results reported at the bottom of Table 7 confirm that all full VIF values met the requirement. This study also performed the Common Method Bias (CMB) assessment using Harman's single-factor test. Firstly, the study analyzed all indicators by extracting a single factor in the principal component analysis. It showed that the one-factor solution explained only $31.04 \%$ of the variance which was lower than the 50\% threshold. Moreover, the result showed that the single-factor confirmatory factor analysis model did not fit the data well $(\chi 2=12003.011$; d.f. $=2032 ; p<.001)$, confirming that CBM is not a serious issue in the analysis model did not fit the data well $\left(\chi^{2}=12003.011\right.$; d.f. $\left.=2032 ; p<.001\right)$, confirming that $C B M$ is not a serious issue in the analysis. 
Table 6: Correlation Among Variables and Square Root of AVE

\begin{tabular}{lcccccccccc}
\hline Variables & PU & PEOU & BI & TRS & RSK & GEN & AGE & EDU & INC & GER \\
\hline PU & $(.87)$ & $.65^{* *}$ & $.67^{* *}$ & $.59^{* *}$ & $-.51^{* *}$ & .06 & $-.08^{*}$ & .00 & $.15^{* *}$ & $.23^{* *}$ \\
PEOU & & $(.87)$ & $.56^{* *}$ & $.52^{* *}$ & $-.50^{* *}$ & .00 & $-.09^{*}$ & -.04 & $.11^{* *}$ & $.21^{* *}$ \\
BI & & & $(.89)$ & $.54^{* *}$ & $-.46^{* *}$ & .05 & -.02 & -.05 & $.14^{* *}$ & $.17^{* *}$ \\
TRS & & & & $(.93)$ & $-.60^{* *}$ & $.09^{*}$ & -.05 & -.06 & $.13^{* *}$ & $.32^{* *}$ \\
RSK & & & & & $(.93)$ & $-.08^{*}$ & -.03 & $.11^{* *}$ & $-.17^{* *}$ & $-.40^{* *}$ \\
GEN & & & & & & $(1)$ & $.11^{* *}$ & .00 & $.14^{* *}$ & .02 \\
AGE & & & & & & & $(1)$ & -.03 & $.15^{* *}$ & $.11^{* *}$ \\
EDU & & & & & & & & $(1)$ & $.34^{* *}$ & $-.20^{* *}$ \\
INC & & & & & & & & & $(1)$ & $.18^{* *}$ \\
GER & & & & & & & & & & $(1)$ \\
\hline
\end{tabular}

The square roof of AVE is shown in parentheses.

$\mathrm{PU}=$ perceived usefulness of online marketplace, PEOU=perceived ease of use of online marketplace, $\mathrm{BI}=$ online shopping intention, TRS=trust in the sellers, $\mathrm{RSK}=$ perceived sellers' risk, GEN=gender, $\mathrm{AGE}=$ age, $\mathrm{EDU}=$ education, $\mathrm{INC}=$ income, GER=nationality (German=1, Thai=0).

The results from PLS-SEM analysis are reported in Table 7.

Hypothesis 1 proposes a positive relationship between perceived usefulness of online marketplaces and the intention to repurchase in online marketplaces. The results shown in Model $1(\beta=.444 ; \mathrm{p}<.001)$ and Model $2(\beta=.433 ; \mathrm{p}<.001)$ indicate the positive association, which is also statistically significant. Thus, Hypothesis 1 is supported.

Hypothesis 2 proposes a positive relationship between perceived ease of use of online marketplaces and the intention to repurchase in online marketplaces. The results shown in Model $1(\beta=.16 ; \mathrm{p}<.001)$ and Model $2(\beta=.172 ; \mathrm{p}<.001)$ indicate the positive association, which is also statistically significant. Thus, Hypothesis 2 is supported.

Hypothesis 3 proposes a positive relationship between trust in the sellers and the intention to repurchase in online marketplaces. The results shown in Model 1 ( $\beta=.166$; $\mathrm{p}<.001)$ and Model $2(\beta=.165 ; \mathrm{p}<.001)$ indicate the positive association, which is also statistically significant. Thus, Hypothesis 3 is supported.

Hypothesis 4 proposes a negative relationship between perceived sellers' risk and the intention to repurchase in online marketplaces. The results shown in Model 1 $(\beta=-.067=; p<.001)$ and Model $2(\beta=-.063 ; p=.025)$ indicate the negative association, which is also statistically significant. Thus, Hypothesis 4 is supported.

Hypothesis 5 proposes that the positive relationship between perceived usefulness of online marketplaces and the intention to repurchase in online marketplaces is stronger in the culture high in masculinity. The result shows that the interaction between perceived usefulness and the German dummy variable is negative and is statistically significant $(\beta=-.084 ; p=.004)$, indicating that the effect of perceived usefulness on the intention to repurchase in online marketplaces was lower in German respondents than in Thai respondents. Given that the German respondents had a lower masculinity score than Thai respondents, Hypothesis 5 is supported.

Hypothesis 6 proposes that the positive relationship between perceived ease of use of online marketplaces and the intention to repurchase in online marketplaces is stronger 
in the culture high in uncertainty avoidance. The result in Model 2 shows that the interaction between perceived ease of use and the German dummy variable is negative and is statistically significant $(\beta=-.08 ; \mathrm{p}=.006)$, indicating that the effect of perceived ease of use on the intention to repurchase in online marketplaces is lower in German respondents than in Thai respondents. Given that the German respondents had a lower uncertainty avoidance score than did Thai respondents, Hypothesis 6 is supported.

Hypothesis 7 proposes that the positive relationship between trust in the sellers and the intention to repurchase in online marketplaces is stronger in the culture high in collectivism. The result in Model 2 shows that the interaction between trust in the sellers and German dummy variable is negative and is statistically significant $(\beta=-.055$; $\mathrm{p}=.042$ ), indicating that the effect of trust in the sellers on the intention to repurchase in online marketplaces is lower in German respondents than in Thai respondents. Given that the German respondents had a lower collectivism score than Thai respondents, Hypothesis 7 is supported.

Hypothesis 8 proposes that the negative relationship between perceived sellers' risk and the intention to repurchase in online marketplaces is stronger in the culture high in uncertainty avoidance. The result in Model 2 shows that the interaction between perceived sellers' risk and the German dummy variable is positive; however, the result is not statistically significant $(\beta=.006 ; \mathrm{p}=.422)$. Therefore, Hypothesis 8 is not supported.

Table 7: Results from PLS-SEM Analysis

\begin{tabular}{lcc}
\hline Variables & $\begin{array}{c}\text { Dependent variable: } \\
\text { Model 1 }\end{array}$ & $\begin{array}{c}\text { Behavioral intention } \\
\text { Model 2 }\end{array}$ \\
\hline Main independent variables & & \\
Perceived usefulness & $.444^{* * *}$ & $.433^{* * *}$ \\
Perceived ease of use & $.16^{* * *}$ & $.172^{* * *}$ \\
Trust in the sellers & $.166^{* * *}$ & $.165^{* * *}$ \\
Perceived sellers' risk & $-.067^{*}$ & $-.063^{*}$ \\
Interacting variables & & \\
Perceived usefulness $\times$ German & $\mathrm{n} / \mathrm{a}$ & $-.084^{* *}$ \\
Perceived ease of use $\times$ German & $\mathrm{n} / \mathrm{a}$ & $-.08^{* *}$ \\
Trust in the sellers $\times$ German & $\mathrm{n} / \mathrm{a}$ & $-.055^{*}$ \\
Perceived sellers' risk $\times$ German & $\mathrm{n} / \mathrm{a}$ & .006 \\
Control variables & & \\
German & $-.077^{* *}$ & $-.055^{*}$ \\
Gender (male=1; female=0) & -.008 & -.01 \\
Age & .03 & .031 \\
Education & $-.057^{*}$ & $-.053^{*}$ \\
Income & $.057^{*}$ & $.06^{*}$ \\
$\mathrm{R}^{2}$ & .504 & .511 \\
$\Delta \mathrm{R}^{2}$ & $\mathrm{n} / \mathrm{a}$ & .07 \\
Maximum Full VIF & 2.5 & 2.527 \\
\hline
\end{tabular}

Notes: $* \mathrm{p} \leq .05, * * \mathrm{p} \leq 0.01,{ }^{* * *} \mathrm{p} \leq 0.001$

Standardized beta coefficients are reported. 
Figure 1: Moderating Effect
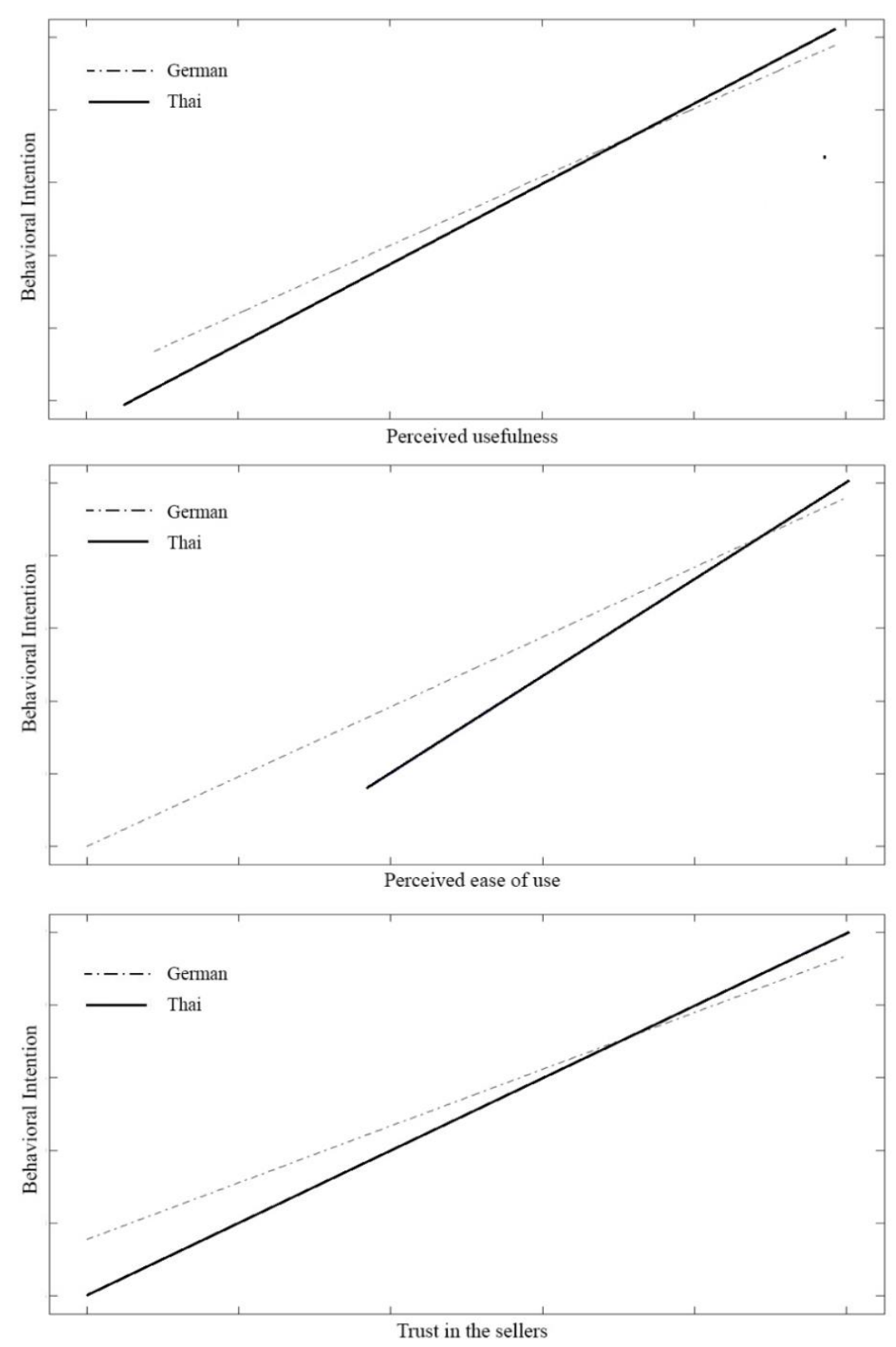

The graphs of the statistically significant moderating effects were plotted using simple slope analysis and are illustrated in Figure 1. The regression slopes that represent the effect of perceived usefulness, perceived ease of use, and trust in the sellers were higher in Thai respondents than in German respondents. These illustrations are consistent with the argument in the hypotheses that suggested that Thai respondents, who are characterized by higher masculinity, uncertainty avoidance, and collectivism tended to rely more on perceived usefulness, perceived ease of use, and trust in the sellers to determine their intention to repurchase in online marketplaces than did their German counterparts, who score lower in these cultural characteristics. 


\section{Discussion and Conclusion}

\section{Discussion of the Results}

This research examined the effects of perceived usefulness, perceived ease of use, trust in the sellers, and perceived sellers' risk on Thai and German respondents' the intention to repurchase in online marketplaces. The study also integrated the theoretical framework of cultural values to examine the aspects of the cultural differences between Thais and Germans and explore the way the effects of perceived usefulness, perceived ease of use, trust in the sellers, and perceived sellers' risk on the intention to repurchase in online marketplaces might differ between these two nationalities.

Firstly, the results from the data analysis supported the significant effect of the variables on the intention to repurchase in online marketplaces on both the Thai and German respondents. These results are consistent with those of prior research that confirmed these factors' role. Similar results were found in research that analyzed these relationships in online shopping for several different countries (Gefen et al., 2003; Gefen \& Pavlou, 2012; Pavlou, 2003; Yoon, 2009). Further, studies in other technological contexts, e.g., internet banking (Martins et al., 2014) and mobile payment (Alshare \& Mousa, 2014) supported these results.

Although perceived usefulness, perceived ease of use, trust in the sellers, and perceived sellers' risk were found to have a significant relationship with both Thai and German respondents' intention to repurchase in online marketplaces, the moderating effect analysis found in addition that the degree to which each of these factors influenced the intention to repurchase in online marketplaces on the part of the respondents of both nationalities differed. In particular, the analysis showed that their effects were significantly higher in the Thai than in the German respondents, implying that Thai respondents' intention to repurchase in online marketplaces tended to be influenced by these factors to a higher degree than in the case of the German respondents. The theoretical reason could be explained by the cultural characteristics of the Thai respondents, who were significantly higher in masculinity, uncertainty avoidance, and collectivism than were the German respondents. The differences in the cultural dimensions of masculinity and uncertainty avoidance are not consistent with Hofstede et al.'s (2010) findings. While Hofstede et al. (2010) analyzed employees in the workplace, this study focused on online consumers, which may have different cultural characteristics in the online shopping context (Lu et al., 2017). However, the results provide additional support for prior research that found that cultural differences influence individual's technology adoption and use, e.g., Alshare and Mousa (2014), Hung and Chou (2014), and Lu et al.'s (2017) studies. Nevertheless, the analysis did not find that the effect of perceived sellers' risk on the intention to repurchase in online marketplaces differed significantly between the two nationalities. This implies that both the Thai and German respondents tended to be concerned to same degree about perceived sellers' risk when making purchases in online marketplaces again.

\section{Research Contribution}

Overall, the findings from this study offer contributions to cultural and e-commerce research. First, the study analyzed the influence of technological predictors, i.e., perceived usefulness and perceived ease of use, and social predictors, i.e., trust in the 
sellers and perceived sellers' risk, in a cross-country comparison. The results provided additional evidence to prior research that showed that both types of predictors combined contribute to the intention to repurchase in online marketplaces. Hence, researchers should pay attention to both aspects in the consumer technology acceptance context. Second, it extended prior research by analyzing these predictors in two distinct countries and comparing the differences in their influence on the intention to repurchase in online marketplaces between the countries. This study provides insights into two countries that have been examined in e-commerce research rarely. Thus, this study provided cross-country validation of concepts that have not been applied combined to these countries to date. More importantly, the results contribute to the research on culture's role in the context of online marketplaces, as it integrated the theoretical framework of cultural values. The findings indicated that cultural dimensions, i.e., masculinity, uncertainty avoidance, and collectivism are able to explain differences in online shopping between countries and cultures. Thus, scholars should consider integrating cultural values into their e-commerce research when findings differ between countries.

\section{Suggestions for Future Research}

The results of this research were obtained from a survey that was conducted in two countries. More countries need to be examined to generalize the results. Further, other studies might use an experimental approach or observe the items that measured the constructs of the framework in this study. Perceived usefulness, perceived ease of use, trust, and risk are holistic constructs but make it difficult to draw inferences about detailed reasons. Future studies should explore the culture's influence on the subdimensions of these constructs in more detail.

\section{Limitations}

Despite the contribution this research provides, the study has certain limitations that need to be considered. First, self-reported measures were used in the survey, and selfevaluation can create subjective bias and may lead to common method bias. Second, the data were collected from consumers with previous online marketplace experience only, which can limit the ability to generalize the results. In particular, the results for trust and risk perceptions may be different for inexperienced consumers who have never purchased online. Third, the results of this study may be influenced by self-selection bias. Moreover, given that there were certain major demographic differences between the Thai and German respondents, such as income and education, it is possible that these differences affected the results.

\section{Implications for Asian Business Context}

This research offers several implications for stakeholders in the online shopping industry, not only for international companies in general, but also for Asian businesses specifically. In particular, this study provided valuable insight to managers, providers, and operators of online marketplaces who develop strategies for cross-country standardization and localization to promote online consumers' use of their online marketplaces. The factors analyzed in this study showed different influences on consumers' intention to repurchase in online marketplaces in two different countries. 
Thus, international companies' managers and cross-cultural marketers may have to develop different strategies for different countries that consider consumers' cultural characteristics.

On the one hand, the results showed that perceived usefulness, perceived ease of use, trust in the sellers, and perceived sellers' risk were important in Thailand and in Germany. Based on these findings, we suggest that marketers' standardization strategy should focus on developing and offering an online shopping platform that is efficient and easy to use and comprising sellers who are trustworthy and pose a low risk to consumers in general. On the other hand, the influence of perceived usefulness, perceived ease of use, and trust in the sellers on the repurchase intention in online marketplaces was higher in Thailand than in Germany. Therefore, marketers' localization strategies should adapt the online marketplace differently to the target markets in these two countries.

Asian companies that target the Thai online market should ensure that they provide an effective and motivating online shopping experience in Thailand. This is supported by the Thai government's investments that are focusing heavily on expanding infrastructure and fostering e-commerce usage for sellers and consumers. Further, managers of online marketplaces should focus on designing clear and intelligible interfaces and services for online shopping in Thailand. These interfaces and services should be simple to navigate and fit Thai consumers' preference to invest low physical and cognitive effort to use online marketplaces. The lack of face-to-face communication in online shopping might not fit Thai consumers' communication style, and while bargaining is part of shopping at local vendors, negotiating prices can be more difficult in online shopping. As Thai consumers are also heavy social media users, integrating social interaction (e.g., online chat with sellers, consumer feedback, and sellers' ratings and their response rate) into the online marketplace may help increase consumers' trust in the sellers and their intention to use these marketplaces again to make purchases online. Managers of online marketplaces in Thailand should also focus on sorting out sellers whose behavior might have a negative influence on the online consumers trust in the community of sellers. This can be supported by increased legal actions by the Thai government or similar authorities who can impose sanctions against sellers with opportunistic behavior.

Asian companies that target the German online market should keep in mind that the performance and ease of use of the online marketplace, and trustworthiness of the sellers are also important in Germany, but other noncognitive, affective factors might exist that can explain more variance in the intention to repurchase in the online marketplace. For example, habit might play an important role for online consumer in Germany. The online market in Germany is characterized by a high market share of the online marketplace amazon.de and a high percentage of online shoppers in general compared to other countries worldwide. Further, well established infrastructure, and laws and legal regulations for online shopping exist in Germany. Thus, German online consumers are used to have an efficient, clearly structured, secure, and reliable online marketplace experience.

Incorporating these insights into their business development and marketing strategies will help Asian companies to adapt successfully to multinational markets and crosscultural consumers not only in Asia but globally. 


\section{References}

Aldousari, A. A., Delafrooz, N., Ab Yajid, M. S., \& Ahmed, Z. U. (2016). Determinants of consumers' attitudes toward online shopping. Journal of Transnational Management, 21(4), 183-199. https://doi.org/10.1080/15475778.2016.1226658

Alshare, K., \& Mousa, A. (2014). The moderating effect of espoused cultural dimensions on consumer's intention to use mobile payment devices. Thirty Fifth International Conference on Information Systems, 1-15.

Andres, L. (2012). Designing and doing survey research: Sage.

Bagozzi, R. P., \& Yi, Y. (1988). On the evaluation of structural equation models. Journal of the Academy of Marketing Science, 16(1), 74-94.

Bauer, R. A. (1960). Consumer behavior as risk taking. Dynamic Marketing for a Changing World, 384-398.

Beugelsdijk, S., \& Welzel, C. (2018). Dimensions and dynamics of national culture: Synthesizing Hofstede with Inglehart. Journal of Cross-Cultural Psychology, 49(10), 1469-1505.

Chang, H. H., Fu, C. S., \& Jain, H. T. (2016). Modifying UTAUT and innovation diffusion theory to reveal online shopping behavior: Familiarity and perceived risk as mediators. Information Development, 32(5), 1757-1773.

Chang, M. K., Cheung, W., \& Tang, M. (2013). Building trust online: Interactions among trust building mechanisms. Information \& Management, 50(7), 439-445.

Chaparro-Peláez, J., Agudo-Peregrina, Á. F., \& Pascual-Miguel, F. J. (2016). Conjoint analysis of drivers and inhibitors of e-commerce adoption. Journal of Business Research, 69(4), 1277-1282. https://doi.org/10.1016/j.jbusres.2015.10.092

Charoensukmongkol, P. (2020). The efficacy of cultural intelligence for adaptive selling behaviors in cross-cultural selling: The moderating effect of trait mindfulness. Journal of Global Marketing, 33(3), 141-157. https://doi.org/10.1080/08911762.2019.1654586

Charoensukmongkol, P., \& Pandey, A. (2020). The influence of cultural intelligence on sales self-efficacy and cross-cultural sales presentations: does it matter for highly challengeoriented salespeople? Management Research Review.

Chin, W. W. (1998). The partial least squares approach to structural equation modeling. Modern Methods for Business Research, 295(2), 295-336.

Chopdar, P. K., Korfiatis, N., Sivakumar, V. J., \& Lytras, M. D. (2018). Mobile shopping apps adoption and perceived risks: A cross-country perspective utilizing the Unified Theory of Acceptance and Use of Technology. Computers in Human Behavior, 86, 109-128. https://doi.org/10.1016/j.chb.2018.04.017

Davis, F. D., Bagozzi, R. P., \& Warshaw, P. (1989). User acceptance of computer technology: a comparison of two theoretical models. Management Science, 35(8), 982-1003.

Driediger, F., \& Bhatiasevi, V. (2019). Online grocery shopping in Thailand: Consumer acceptance and usage behavior. Journal of Retailing and Consumer Services, 48, 224 237. https://doi.org/10.1016/j.jretconser.2019.02.005

Flavián, C., \& Guinalíu, M. (2006). Consumer trust, perceived security and privacy policy. Industrial Management \& Data Systems, 106(5), 601-620.

Fornell, C., \& Larcker, D. F. (1981). Evaluating structural equation models with unobservable variables and measurement error. Journal of Marketing Research, 18(1), 39-50.

Gefen, D., Karahanna, E., \& Straub, D. W. (2003). Trust and TAM in online shopping: An integrated model. MIS Quarterly, 27(1), 51-90.

Gefen, D., \& Pavlou, P. A. (2012). The boundaries of trust and risk: The quadratic moderating role of institutional structures. Information Systems Research, 23(3-part-2), 940-959.

Hall, E. T. (1989). Beyond culture: Anchor.

Hallikainen, H., \& Laukkanen, T. (2018). National culture and consumer trust in e-commerce. International Journal of Information Management, 38(1), 97-106. https://doi.org/10.1016/j.ijinfomgt.2017.07.002 
Henseler, J., Ringle, C. M., \& Sarstedt, M. (2015). A new criterion for assessing discriminant validity in variance-based structural equation modeling. Journal of the Academy of Marketing Science, 43(1), 115-135.

Hofstede, G. (2001). Culture's consequences: Comparing values, behaviors, institutions and organizations across nations: Sage Publications.

Hofstede, G., Hofstede, G. J., \& Minkov, M. (2010). Cultures and Organizations: Software of the Mind: Intercultural Cooperation and Its Importance for Survival (3rd ed.). New York: McGraw-Hill Education Ltd.

Hung, C.-L., \& Chou, J. C.-L. (2014). Examining the cultural moderation on the acceptance of mobile commerce. International Journal of Innovation and Technology Management, 11(02), 1450010.

Israel, G. D. (1992). Determining sample size: University of Florida Cooperative Extension Service, Institute of Food and Agriculture Sciences, EDIS.

Kock, N., \& Hadaya, P. (2018). Minimum sample size estimation in PLS-SEM: The inverse square root and gamma-exponential methods. Information Systems Journal, 28(1), 227-261.

Lu, J., Yu, C.-S., Liu, C., \& Wei, J. (2017). Comparison of mobile shopping continuance intention between China and USA from an espoused cultural perspective. Computers in Human Behavior, 75, 130-146. https://doi.org/10.1016/j.chb.2017.05.002

Marriott, H. R., \& Williams, M. D. (2018). Exploring consumers perceived risk and trust for mobile shopping: A theoretical framework and empirical study. Journal of Retailing and Consumer Services, 42, 133-146.

Martins, C., Oliveira, T., \& Popovič, A. (2014). Understanding the Internet banking adoption: A unified theory of acceptance and use of technology and perceived risk application. International Journal of Information Management, 34(1), 1-13. https://doi.org/10.1016/j.ijinfomgt.2013.06.002

McCoy, S., Galletta, D. F., \& King, W. R. (2005). Integrating national culture into IS research: The need for current individual level measures. Communications of the Association for Information Systems, 15(1), 12.

Natarajan, T., Balasubramanian, S. A., \& Kasilingam, D. L. (2017). Understanding the intention to use mobile shopping applications and its influence on price sensitivity. Journal of Retailing and Consumer Services, 37, 8-22. https://doi.org/10.1016/j.jretconser.2017.02.010

Pandey, A., \& Charoensukmongkol, P. (2019). Contribution of cultural intelligence to adaptive selling and customer-oriented selling of salespeople at international trade shows: does cultural similarity matter? Journal of Asia Business Studies, 13(1), 79-96. https://doi.org/10.1108/JABS-08-2017-0138

Pavlou, P. A. (2003). Consumer acceptance of electronic commerce: Integrating trust and risk with the technology acceptance model. International Journal of Electronic Commerce, 7(3), 101-134.

Pavlou, P. A., \& Gefen, D. (2004). Building effective online marketplaces with institutionbased trust. Information Systems Research, 15(1), 37-59.

Phungsoonthorn, T., \& Charoensukmongkol, P. (2019). Antecedents and outcomes associated with a sense of place toward the organization of Myanmar migrant workers in Thailand. Equality, Diversity and Inclusion: An International Journal, 39(2), 195-218. https://doi.org/10.1108/EDI-06-2019-0177.

Pongton, P., \& Suntrayuth, S. (2019). Communication Satisfaction, Employee Engagement, Job Satisfaction, and Job Performance in Higher Education Institutions. ABAC Journal, 39(3), 90-110.

Puyod, J. V., \& Charoensukmongkol, P. (2019). The Contribution of Cultural Intelligence to the Interaction Involvement and Performance of Call Center Agents in Cross-Cultural Communication. Management Research Review, 42(12), 1400-1422. https://doi.org/10.1108/MRR-10-2018-0386

Ratasuk, A., \& Charoensukmongkol, P. (2020). Does cultural intelligence promote crosscultural teams' knowledge sharing and innovation in the restaurant business? Asia- 
Pacific Journal of Business Administration, 12(2), 183-203.

Rita, P., Oliveira, T., \& Farisa, A. (2019). The impact of e-service quality and customer satisfaction on customer behavior in online shopping. Heliyon, 5(10), e02690.

Rotter, J. B. (1967). A new scale for the measurement of interpersonal trust 1. Journal of Personality, 35(4), 651-665.

Seriwatana, P., \& Charoensukmongkol, P. (2020). Cultural intelligence and relationship quality in the cabin crew team: The perception of members belonging to cultural minority groups. Journal of Human Resources in Hospitality \& Tourism, 1-27. https://doi.org/10.1080/15332845.2020.1821431

Sohaib, O., Kang, K., \& Miliszewska, I. (2019). Uncertainty avoidance and consumer cognitive innovativeness in e-commerce. Journal of Global Information Management, 27(2), 5977. https://doi.org/10.4018/JGIM.2019040104

Srite, M., \& Karahanna, E. (2006). The Role of Espoused National Cultural Values in Technology Acceptance. MIS Quarterly, 30(3), 679-704.

Tarsakoo, P., \& Charoensukmongkol, P. (2019). Dimensions of social media marketing capabilities and their contribution to business performance of firms in Thailand. Journal of Asia Business Studies, 14(4), 441-461. https://doi.org/10.1108/JABS-072018-0204

Venkatesh, V., Thong, J. Y. L., \& Xu, X. (2012). Consumer acceptance and use of information technology: extending the unified theory of acceptance and use of technology. MIS Quarterly, 36(1), 157-178.

Yoo, B., Donthu, N., \& Lenartowicz, T. (2011). Measuring Hofstede's five dimensions of cultural values at the individual level: Development and validation of CVSCALE. Journal of International Consumer Marketing, 23(3-4), 193-210.

Yoon, C. (2009). The effects of national culture values on consumer acceptance of e-commerce: Online shoppers in China. Information \& Management, 46(5), 294-301. 